Stage IV. Head rounded, scarcely bilobed, lower than prothorax, whitish, dotted with black over the sides and in a double streak on the vertex; width about I mm. Body short and thick, angular from the elevations, but without processes. Tubercle i and ii are high white cones with short, stiffs setae but with no elevation of the body ; iv is a larger cone with similar seta (i.e. ii of joint 5 , iv of 6 to 9), the tubercle radiately spinose on its shaft and arising from a slight lateral elevation or swelling of the body; before and a little below it is a smaller smooth white cone bearing seta iii; $\mathrm{v}$ and vi remote, similar to iii; upper vii smaller, below iii subventrally; lower vii and viii are prominent on the edge of the venter. Spiracle on the dorsal aspect of the slight bulge that bears tubercle iv on joints 5 to 9 . 'Tubercles of thorax and joints $12-13$ smaller; on $I 2, i$ is absent, ii is large and sticky like iv of 9 , iii is rudimentary. Blackish gray; ground color blackish brown, densely frosted with round flattened, white granules, the prominent tubercles white and an angular white marking in a double dorsal line, along the angular lateral outline and subventrally, most distinct on joints $\mathrm{I} 2$ and $\mathrm{I} 3$. Thoracic feet pale; plates large, but colored and sculptured like the body. All covered with fragments of petals, adhering to the sticky tubercles. The spicules on the sticky tubercles are short cylindrical rods with blunt tips. The larva hibernated in this stage, full grown apparently. Bred at Washington, D. C., from eggs obtained Sept. 2I. Earlier broods will give the moth the same season.

Larvae fed on flowers of Aster.

\section{NOTES ON THE NESTING OF ANTHIDIUM PAROSELAE CKLL.}

I do not know how long this bee had been working before I discovered it, but to my knowledge it carried honey and pollen into its nest for two days. The nest was a small round hole bored in the hard sand. The bee brought very small loads of pollen, and would remain in its nest about 45 seconds each time; it took from three to five minutes for it to collect each load, and when it returned it would sail about its nest a short time before entering. Once during the absence of the Anthidium a specimen of Sphecodes fortior Ckll. entered the nest and stayed about half a minute, and then flew out very swiftly, as if it were afraid the Anthidium would return and do it some harm. I had noticed from the beginning that another bee (Hoplopasites productus var. subruber Ckll.) lingered around the nest, and would frequently go to the entrance and look in. After a while dur- ing the absence of the Anthidium, it took the liberty of going into the nest, but it did not stay long. After the Anthidium had finished provisioning her nest, she brought some wool from the stems of plants and filled up the entrance. When the bee had gone I dug up the nest and found that it had stored its provisions in wool, the same as that with which it had closed up the nest.

Minnie Newberry.

[The above observations, made by Miss Newberry, a student of the N. M. Agricultural College, are of interest, because nothing whatever has been reported heretofore regarding the nesting of any of the insects mentioned. It is perhaps unsafe to assert that the Sphecodes and Hoplopasites are parasitic in the nest of the Anthidium, but the facts point to such a conclusion. The observations were made at Mesilla Park at the end of May, and I am responsible for the identification of the insects.-T.D.A. Cockerell.] 

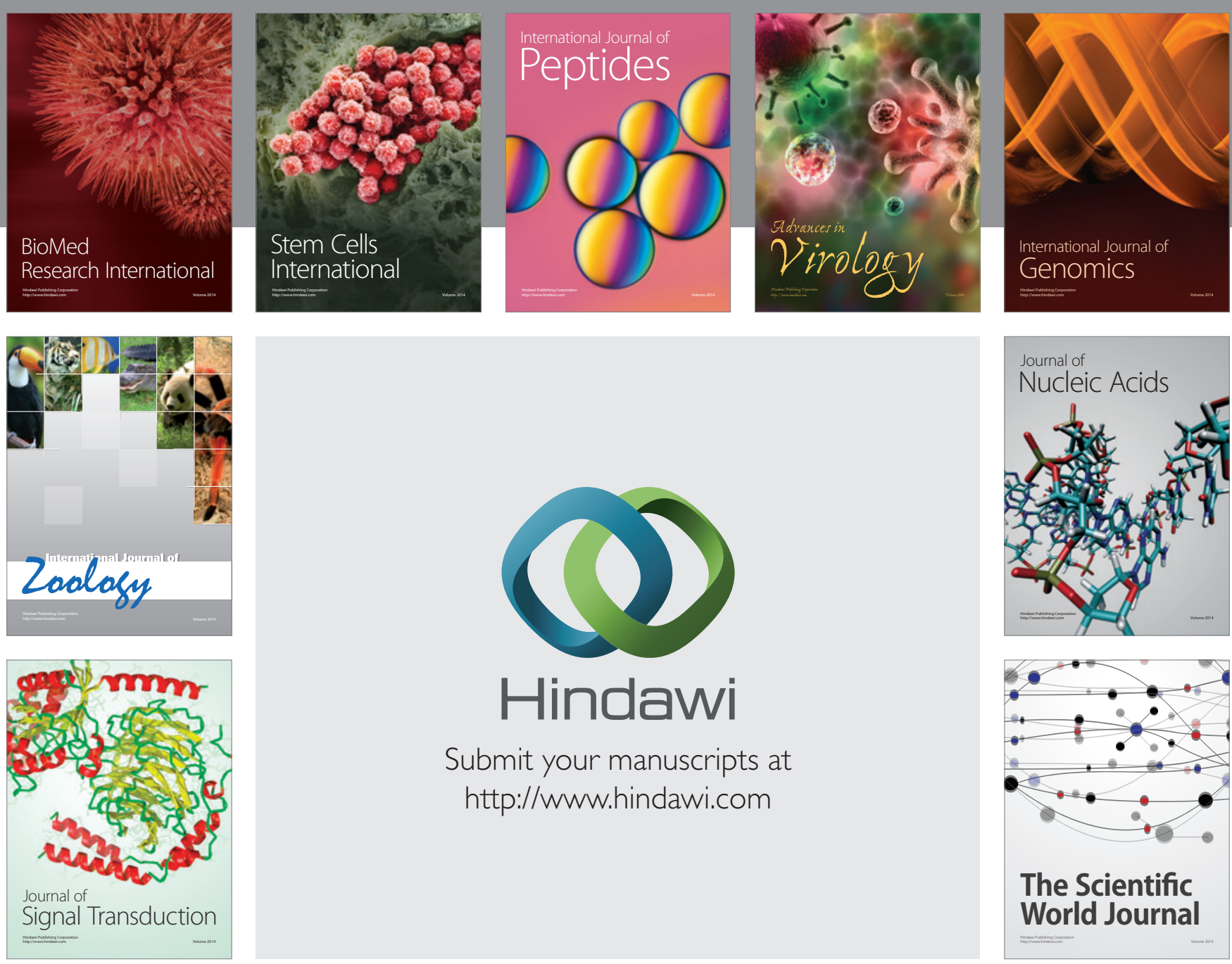

Submit your manuscripts at

http://www.hindawi.com


The Scientific World Journal
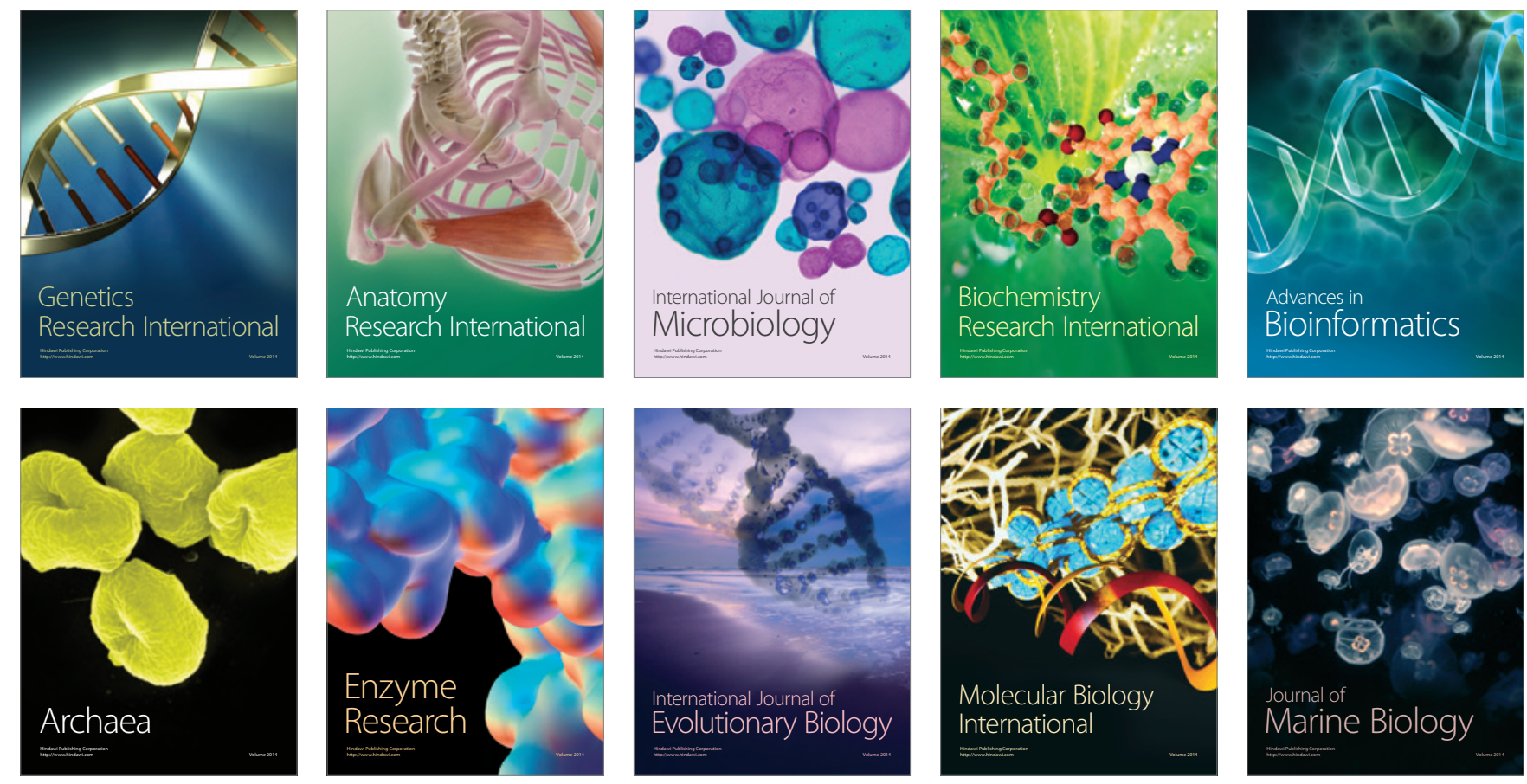